\title{
TRANSCORPOREAL CERVICAL FORAMINOTOMY: DESCRIPTION OF TECHNIQUE AND RESULTS
}

\author{
FORAMINOTOMIA CERVICAL TRANSCORPORAL: DESCRIÇÃO DA TÉCNICA E DOS RESULTADOS
}

\section{FORAMINOTOMÍA CERVICAL TRANSCORPORAL: DESCRIPCIÓN DE LA TÉCNICA Y DE LOS RESULTADOS}

Guilherme Pereira Corrêa Meyer¹, Gun Chol ${ }^{1}$, Amit Bandharkar ${ }^{1}$, Pll Sun Chol ${ }^{2}$, Sang Ho Lee ${ }^{1}$, Alexandre Fogaça Cristante², Raphael Martus Marcon², Alexandre Sadao lutaka², Tarcísio Eloy Pessoa de Barros².

\begin{abstract}
Objective: Retrospective analyses of 216 patients undergoing foraminal decompression with transcorporeal approach and review of the surgical technique. Method: 216 patients with minimum follow-up of 2 years and an average of 41.8 months were included in the study. The clinical records of these patients were reviewed for complications, NDI (neck disability index) and VAS (visual analogue scale). Pre and post-operative radiographs were used to evaluate the disc height. Results: At the end of follow-up patients had significant clinical improvement with reduction of $\mathrm{NDI}$ of $88.3 \%$ and $86.5 \%$ and $68.3 \%$ of the VAS for neck and upper limb, respectively $(p<0.05)$. A reduction of $8.8 \%$ of the disc height was observed without other complications associated $(p<0.05)$. Conclusion: Radicular decompression through a transcorporeal approach is an alternative that provides good clinical results without the need for a fusion and with few complications.
\end{abstract}

Keywords: Foraminotomy; Radiculopathy; Spinal diseases; Neurosurgery; Intervertebral disc displacement.

\section{RESUMO}

Objetivo: Análise retrospectiva de 216 pacientes submetidos a descompressão foraminal cervical por abordagem transcorporal e revisão da técnica cirúrgica. Método: Duzentos e dezesseis pacientes com seguimento mínimo de 2 anos e média de 41,8 meses foram incluídos no estudo. Os prontuários desses pacientes foram revisados quanto a complicações, NDI (neck disability index) e EVA (escala visual analógica). Radiografias pré e pós-operatórias foram usadas para avaliar a altura discal. Resultados: Ao final do seguimento, os pacientes obtiveram uma melhora clínica significativa com redução do NDI de 88,3\% e de 86,5\% e 68,3\% da EVA para o membro superior e região cervical, respectivamente $(p<0,05)$. Uma redução de $8,8 \%$ da altura discal foi observada sem outras complicações associadas $(p<0,05)$. Conclusão: A descompressão radicular por abordagem transcorporal é uma alternativa que proporciona bons resultados clínicos, sem a necessidade de uma fusão e com poucas complicações.

Descritores: Foraminotomia; Radiculopatia; Doenças da coluna vertebral; Neurocirurgia; Deslocamento do disco intervertebral.

\section{RESUMEN}

Objetivo: Análisis retrospectivo de 216 pacientes sometidos a descompresión foraminal cervical por abordaje transcorporal y revisión de la técnica quirúrgica. Método: Doscientos dieciséis pacientes con seguimiento mínimo de 2 años y promedio de 41,8 meses fueron incluidos en el estudio. Los prontuarios de esos pacientes fueron revisados cuanto a complicaciones, NDI (neck disability index) y EVA (escala visual analógica). Radiografias pre y postoperatorias fueron usadas para evaluar la altura discal. Resultados: Al final del seguimiento, los pacientes obtuvieron una mejora clínica significativa con reducción del NDI de 88,3\% y de 86,5\% y 68,3\% de la EVA para el miembro superior y región cervical, respectivamente $(p<0,05)$. Una reducción de $8,8 \%$ de la altura discal fue observada sin otras complicaciones asociadas ( $p<0,05)$. Conclusión: La descompresión radicular por abordaje transcorporal es una alternativa que proporciona buenos resultados clínicos, sin la necesidad de una fusión y con pocas complicaciones.

Descriptores: Foraminotomía; Radiculopatía; Enfermedades de la columna vertebral; Neurocirugía; Dislocamiento del disco intervertebral.

\section{INTRODUCTION}

Cervicobrachialgia is a common complaint in doctors' offices. It can be caused by a hernia of a cervical disc, foraminal stenosis, or hypertrophy of the uncinate process leading to a radicular compression. Anterior cervical discectomy and fusion (ACDF) is the most widely used surgical method worldwide, yielding good results. ${ }^{1}$ However, fusion or arthrodesis is not a complication-free procedure. Pseudoarthrosis, ${ }^{2}$ adjacent disc degeneration (ADD), ${ }^{3}$ breakage of the implant, ${ }^{4}$ and subsidence $^{5}$ are the main complications. Posterior foraminotomy is a surgical alternative that preserves movement without the use of any type of implant. However, it can lead to instability when more than $50 \%$ of the facet joint is removed, and it is more suitable for posterior pathologies. ${ }^{6}$ Postoperative paresthesia is a common complication when there is anterior compression, because more manipulation of the root is required to achieve adequate decompression. ${ }^{7}$ Endoscopic techniques through the disc are limited to soft tissue hernias, and are not suitable for the treatment of foraminal stenosis or for resection of osteophytes. These techniques also require extensive training, due to the long learning curve. ${ }^{8}$

1. Department of Neurosugery, Wooridul Spine Hospital, Seoul, South Korea.

2. Instituto de Ortopedia eTraumatologia do Hospital das Clínicas da Faculdade de Medicina da Universidade de São Paulo, São Paulo, SP, Brazil.

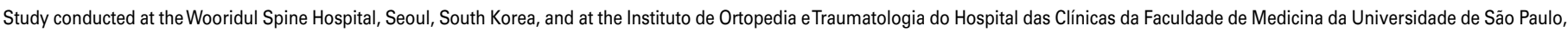
São Paulo, SP, Brazil.

Correspondence: Rua Iraquita, 58, Jardim Paulista. São Paulo, SP, Brasil. 01432-040. gpcmeyer@gmail.com 
Jho et $\mathrm{al}^{9}$ published an anterior foraminotomy for treatment of a unilateral disc hernia and cervical stenosis with removal of the uncinate process.

In 2007, Choi et $\mathrm{al}^{10}$ published a transcorporeal foraminotomy (TCF) as a modification of Jho's technique and its initial results. Later, the author published the clinical outcomes of 30 patients in two-year follow-up. ${ }^{11}$ In this study, our objective is to review the previously described surgical technique, and present the clinical outcomes of more than eight years of experience with the technique considering a minimum follow-up of two years. We also analyze the radiographic evolution, and seek to determine whether there is a significant reduction in disc height.

\section{MATERIALS AND METHODS}

Following approval by the ethics committee of the institution, and in the absence of any conflicts of interest, the medical records of the patients participating in this study were reviewed. This retrospective analysis included 216 patients who underwent radicular decompression by the transcorporeal approach during the period from April 2006 to August 2010, with a minimum follow-up of two years. Among these patients, 38 underwent this procedure at two consecutive levels, giving a total of 254 levels treated. The average follow-up was 41.8 months. The indications for surgery were unilateral radiculopathies caused by herniated discs or foraminal stenosis of the cervical spine. A definite clinical-radiological correlation with magnetic resonance (MRI) and computed tomography (CT) was a fundamental criterion for indicating the procedure. The patients underwent six weeks of conservative treatment with anti-inflammatory medication, analgesics, and motor physiotherapy prior to the indication for surgery. Only those patients whose conditions worsened, and whose pain was not controllable with opioids, were submitted to the procedure before completing the six weeks of conservative treatment. Patients with signs of central compression, myelopathy, and bilateral foraminal compression were excluded from the study.

Of the total of 216 patients, 65 were women and 151 were men, with an average age of 54.4 years. The radiological investigation consisted of radiographs (front, neutral profile, with flexion and with extension), CT, and MRI. An MRI of each patient was performed of each level treated postoperatively, between 6 and 24 hours following the procedure, to evaluate decompression. During clinical follow-up, radiographs were taken at $3,6,12$, and 24 months. Disc height was measured in the preoperative radiographs, and compared with the postoperative radiographs. Disc height was measured at the center of the disc. The VAS (visual analog scale) was used to evaluate pain in the related upper limb and in the cervical region and the NDI (neck disability index) was used for evaluation of function.

\section{Surgical technique}

Among the preoperative exams, the CT was particularly important for better bone detailing and for planning of the entry, trajectory, and depth of the tunnel. (Figure 1) Because a foraminal compromise was suspected, MRI oblique sections were taken to better visualize the foramens. Surgical planning is fundamental, and all the bony prominences and anatomical references should be derived from the exams. The course of the vertebral artery also must be carefully analyzed, as an anatomical abnormality could place it at risk and can lead to a catastrophic outcome.

During surgical planning, the doctor should also pay attention to the level of the injury and to the clinical aspect of the patient's neck. A hernia at level C3-4 makes it difficult to create the tunnel through $\mathrm{C} 3$ in a cranio-caudal direction, and an approach through $\mathrm{C} 4$ from a caudal-cranial angle is required.

The positioning of the patient is a key step in the surgery. The patient must be lying in a supine position without rotational deviations and with the neck slightly extended. A radiotransparent table should be used and, before the procedure begins, orthogonal images of the front and profile of the cervical region should be obtained. This eliminates "shadows" and obstructions in the image. In addition,

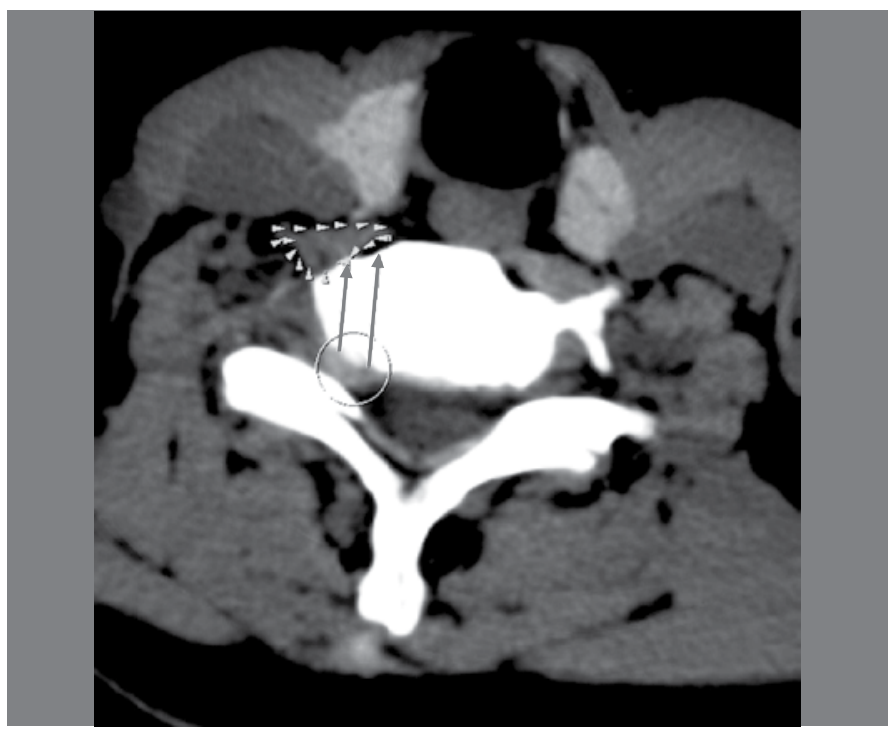

Figure 1. CT Axial section. The long arrows indicate the plan for the bone tunnel. The short arrows indicate the longus colli muscle. The circle shows the disc herniation.

the level to be approached is identified and the location of the cutaneous incision is marked. For removal of non-migrated disc hernias and foraminal stenosis, the cranial level should be used as the reference for the incision. In other words, for us to approach level C5-C6, the cutaneous incision is made in the projection of C4-C5. When the site of the compression is more distally located, as with an inferiorly migrated hernia, the incision is made even more cranially. In inverse situations, the incision must be made caudally in relation to the projection of the cranial level. (Figure 2) To create the tunnel through the distal vertebra, as is done for level C3-4, the projection of the caudal level becomes the reference for the incision. The skin incision, which should be between 3 and 4 centimeters in length, is made in the horizontal direction following the folds of the skin. During surgery, the fluoroscope is used to locate the level for the approach, and also in case of any doubt as to the positioning and direction of the tunnel.

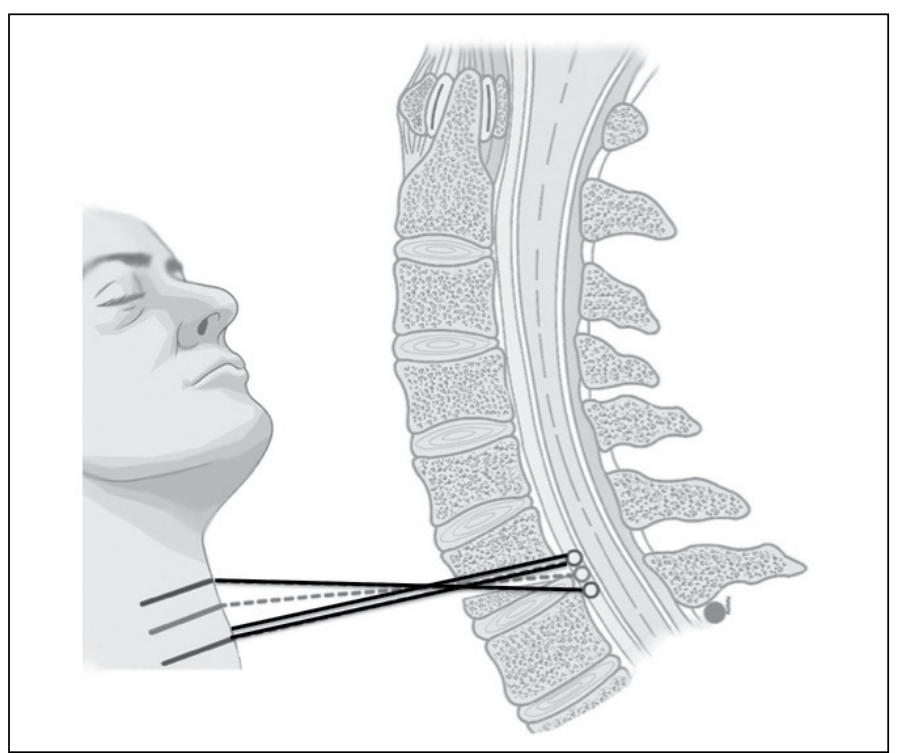

Figure 2. Representation of the site of the cutaneous incision in accordance with the location of the hernia. In non-migrated hernias, the incision is made at the level of the cranial disc (dotted line). In distally migrated herniations, the incision is even more cranial (solid line). In cranially migrated hernias, the incision is slightly more caudal (double solid line). 
The access path used is that of Smith and Robinson, ${ }^{12}$ where the procedure developed moves aside the sternocleidomastoid muscle (SCM) and the carotid artery laterally and the trachea and esophagus medially. Once the cervical spine is visible, the longus colli muscle is dissected unilaterally in subperiosteal form, from medial to lateral. The disc and the body to be treated are exposed, and the blades of the Caspar retractor (Aesculap, Germany) keep the SCM and the carotid artery apart laterally. This exposes the starting point for the creation of the tunnel. Discography with indigo carmine is routinely performed to facilitate orientation during the creation of the tunnel. The entry point for the start of drilling is made $3 \mathrm{~mm}$ above the inferior plateau and $3 \mathrm{~mm}$ medially to the projection of the junction of the body with the transverse process. (Figure 3) The tunnel must be about $5 \mathrm{~mm}$ in diameter, and the direction should be individualized on a case by case basis to reach the target of the compression. Initially, a $4 \mathrm{~mm}$ diamond drill (Synthes, West Chester, PA, USA) is used. The tunnel should be made in spongy bone, using the inferior and lateral cortical bones as references. During drilling, the cortical bone produces a white powder and its resistance is greater. This enables the cortical bone to be differentiated from spongy bone. The inferior cortical bone is the boundary between the body and the disc and should be bypassed in the posterior third. This preserves the disc as a functional unit and allows a precise approach. The lateral cortical bone constitutes the wall of the transverse foramen and contains the vertebral articulation. This limit must not be bypassed, due to a risk of vascular injury and uncontrollable bleeding. Once two thirds of the tunnel is completed, the $4 \mathrm{~mm}$ drill is changed to a $3 \mathrm{~mm}$ drill. In the preoperative CT, the distance of the tunnel is calculated, providing yet another important reference during the procedure.

After two thirds of the drilling, we must advance downwards, visualizing the blue coloration of the indigo carmine. (Figure 4) This indicates that the tunnel is in the correct position and we must continue in the same direction, ensuring the blue dye is always at the center of the drilling. Initially the blue dye is discreet and appears as a thin line. Later, it becomes wider and bluer, indicating that we have reached herniated matter and the center of the disc space (in the case of a disc hernia). A delicate tracer, a modified curette,

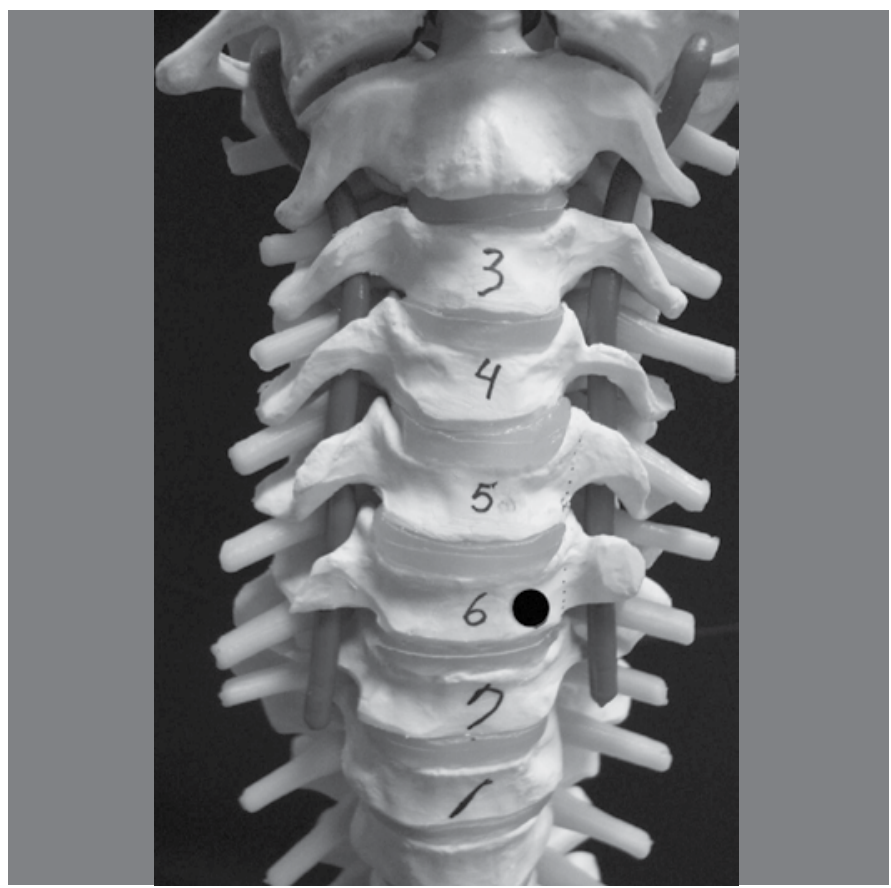

Figure 3. The point of entry for the start of drilling is made $3 \mathrm{~mm}$ above the inferior plateau and $3 \mathrm{~mm}$ medially to the projection of the junction of the body with the transverse process. and pituitary forceps are used to remove the herniated fragment. In patients with foraminal stenosis, the Kerringson 1 and $2 \mathrm{~mm}$ should be used to remove the osteophytes and widen the foramen. We must always be extremely careful with the lateral wall of the tunnel, taking care not to advance into the transverse foramen. Additionally, patients with significant foraminal stenosis have an extremely thin root and care must be taken not to injure it iatrogenically. It is preferable to initiate decompression in a medial to lateral direction, as this facilitates identification of the root.

Radicular decompression allows the spinal fluid to flow, permeating the root and causing this structure to swell. In addition, the inferior margin of the pedicle of the vertebra on question and the superior margin of the pedicle of the caudal vertebra can be palpated. (Figure 5) Both palpation and filling of the root with spinal fluid indicate that decompression was successfully accomplished.

Possible complications include inadequate trajectory of the bone tunnel, incomplete decompression, and bleeding. A careful evaluation of the preoperative exams and the interoperative use of radioscopy reduce the risks of an inadequate trajectory and insufficient decompression. Bleeding can be divided into three types: bone, epidural, and vertebral artery bleeds. Using bone wax to stop bone bleeds is usually effective. Hemostatic agents like Gelfoam ${ }^{\circledR}$ (Pfizer) and Surgicel ${ }^{\circledR}$ (Johnson \& Johnson), as well as bipolar coagulation, are used to stop epidural bleeds. A bleed from a lesion of the vertebral artery can have a catastrophic outcome, and treatment requires a widening of the approach and specific treatment that is not included within the objective of this text. Careful preoperative planning can appreciably reduce the complications. (Figure 6)

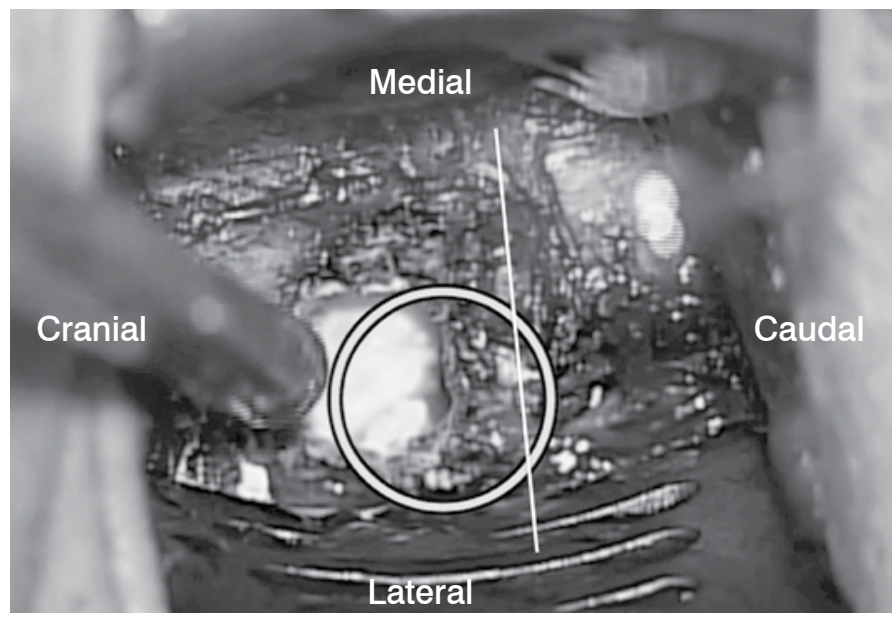

Figure 4. After $2 / 3$ of the drilling, we must advance inferiorly and visualize the blue coloration of the indigo carmine which can be seen in the center of the circle. This is an important reference during the creation of the tunnel.

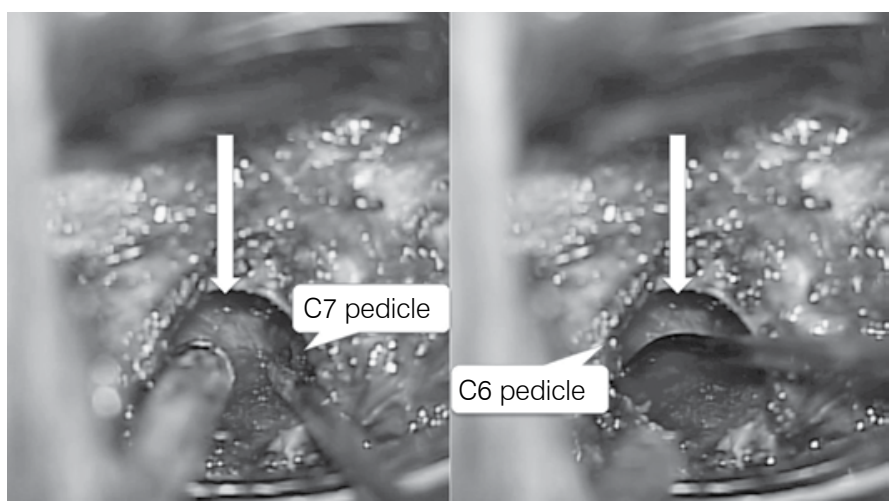

Figure 5. The arrow points from the medial to the lateral and in the center of the tunnel the root can be seen. The margins of the pedicles can be palpated to verify suitable decompression. 


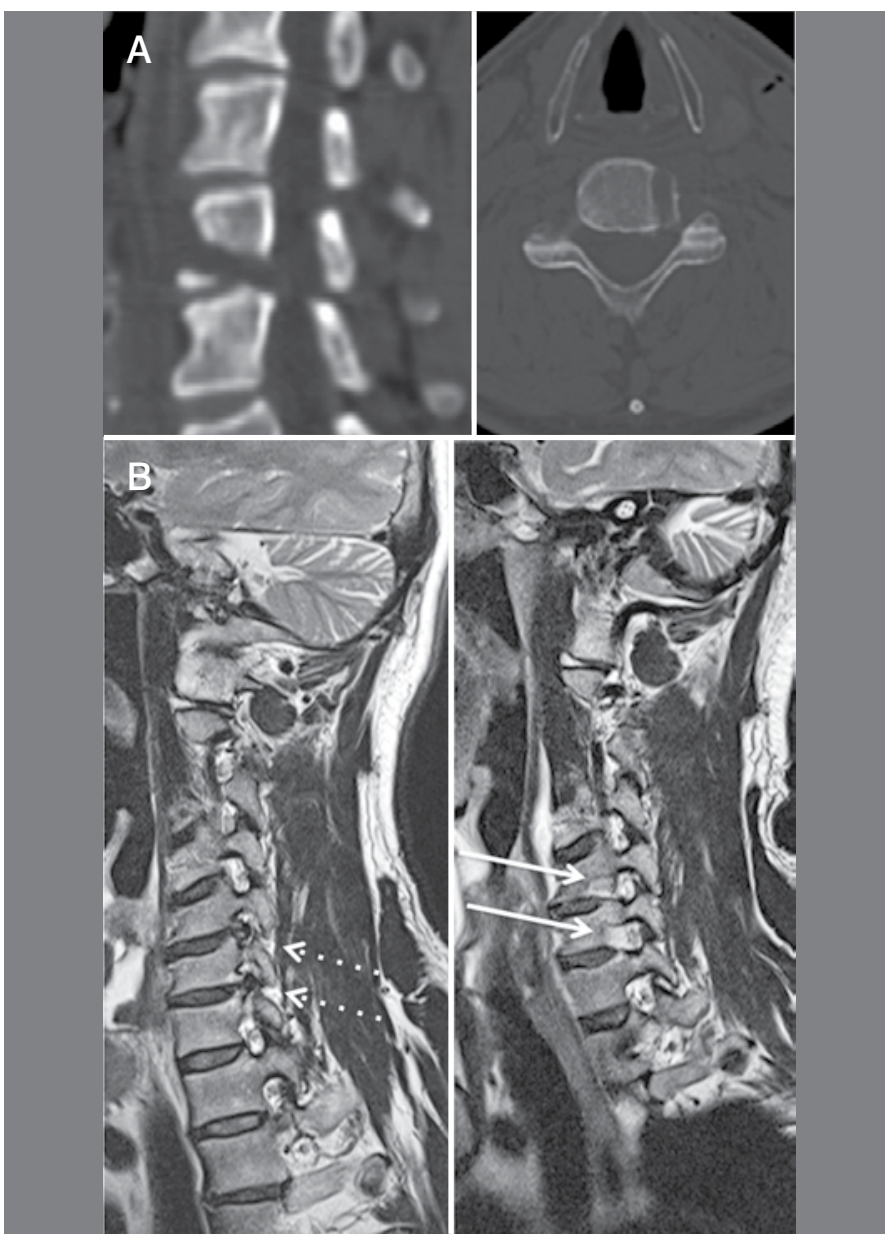

Figure 6. A) Postoperative CT showing the location of the bone tunnel. B) Pre- and postoperative MRIs in a patient who underwent decompression in two levels.

\section{RESULTS}

Most patients reported improvement of symptoms immediately following surgery. The average preoperative value of the NDI was $56.5 \%$ and dropped to $6.6 \%$ by the end of follow-up, representing an improvement of $88.3 \%(p<0.05)$. The average preoperative VAS values were 8.2 and 4.1 for the arm and neck, respectively. At the end of follow-up the values fell to 1.1 and 1.3, representing improvements of $86.5 \%$ and $68.3 \%$, respectively ( $p<0.05$ for both values). (Table 1) The average surgical time was 107 minutes, ranging from 67 to 142 minutes. Average postoperative bleeding was $168 \mathrm{ml}$ and none of the patients required a transfusion. During follow-up, 12 patients underwent a new cervical surgery, five of them at the same level as the transcorporeal approach, five at a different level, and two patients both at the level approached previously and at a different level. In other words, seven patients (3.24\%) were reapproached and five patients $(2.31 \%)$ underwent a new surgery at a different cervical level. ACDF, corpectomy and arthrodesis, posterior foraminotomy, and another TCF were the subsequent procedures used. Among the patients who received a second approach at the same level as the TCF, one patient had discitis, which was resolved following ACDF and antibiotic therapy, two had the same symptoms and imaging exams revealed insufficient decompression, and four patients had progression of degenerative disc disease. Seven patients underwent surgery in which the adjacent level was included (3.24\%). Eight patients reported postoperative dysphagia (3.7\%) one of whom had a large cervical hematoma that was surgically drained without further complications. The symptoms of the other patients were resolved within 3 months. The average preoperative disc height was $7.9 \mathrm{~mm}$ and at the end of follow-up it was $7.2 \mathrm{~mm}$. Although this represents a reduction of $8.8 \%(p<0.05)$, we did not observe any other complications associated with this reduction in disc height.

Table 1. The table shows postoperative improvement represented by a drop in NDI and VAS both for the upper limb and cervical spine.

\begin{tabular}{c|c|c|c|c}
\hline & Pre & Post & Improvement & \\
\hline NDI & $56.50 \%$ & $6.60 \%$ & $88.30 \%$ & $(\mathrm{p}<0.0 .5)$ \\
\hline Upper limb VAS & 8.2 & 1.1 & $86.50 \%$ & $(\mathrm{p}<0.0 .5)$ \\
\hline Cervical spine VAS & 4.1 & 1.3 & $68.30 \%$ & $(\mathrm{p}<0.0 .5)$ \\
\hline
\end{tabular}

\section{DISCUSSION}

ACDF is considered to be the gold standard treatment for disc pathologies of the cervical spine. First described by Smith and Robinson ${ }^{12}$ and later modified by Cloward, ${ }^{13}$ this method has provided satisfactory outcomes for a variety of cervical diseases. Foraminal stenosis, herniated cervical disc, and ossification of the posterior longitudinal ligament with nerve compression are among the diseases treated in this way. It is a technique that offers satisfactory and very predictable results. Nonetheless, it is not free from either immediate or long-term complications. ${ }^{3,4}$ The most common immediate complications are dysphagia, bleeding and hematomas, paralysis of the recurrent laryngeal nerve, hoarseness, laceration of the esophagus and trachea, and occasionally, laceration of the dura mater. ${ }^{4,14}$ The complaint of dysphagia is one of the most common complications and has an incidence of $30 \%$ after three months according to Riley et al. ${ }^{14}$ In our study we found 8 cases out of 216 patients representing $3.7 \%$ of the sample. Transcorporeal foraminotomy is a procedure that does not require significant exposure of the cervical spine or retraction of the soft tissue because only one side of the spine is approached. The side opposite the pathology remains intact. To perform discectomy or arthrodesis, the entire anterior section of the cervical spine is exposed creating great pressure from the medial retractor against the esophagus and the trachea. Transcorporeal foraminotomy is also a procedure of short duration, which helps reduce the complications. ${ }^{6}$

Complications such as implant failure, pseudoarthrosis, migration, or subsidence of the cage do not apply to this technique, since fusion is not performed. ${ }^{5,15}$ Complications associated with the graft and donor site, as in the case of an iliac graft, also do not apply. ${ }^{16}$

In our study, we did not observe any dural or vertebral artery lesions. The main differences in the anterior foraminotomy described by $\mathrm{JhO}^{17}$ are the more lateral point of entry and the creation of the tunnel through the uncinate process. Lesion of the vertebral artery is a potential complication of this approach. ${ }^{9}$ We believe that we had no vertebral artery lesions because the bone tunnel created using the technique described preserves the lateral wall of the body (medial cortical of the transverse foramen). We believe the complete removal of the uncinate process can cause instability in the mid and long term. In our technique, the tunnel through the vertebral body leaves the anterior portion of the disc and part of the uncinate process intact, preserving the function of the segment.

In 1968, Verbiest ${ }^{18}$ described an anterolateral approach. However, his technique is difficult to perform and Horner's syndrome is a possible complication due to the more lateral approach to the cervical spine with complete exposure of the transverse process. Jho et $\mathrm{al}^{9}$ also describe two patients with Horner's syndrome with spontaneous resolution of the symptoms in six weeks. In our study, we did not observe any cases of Horner's syndrome, as exposure of the transverse process was limited to the more medial portion, used as an anatomical reference.

ADD to a fusion is a complication that has been extensively stu-

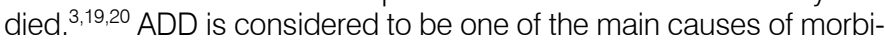
dity following arthrodesis. It is defined as a new nerve compression with the presence of new symptoms associated with these changes in a segment adjacent to a prior fusion. ${ }^{20}$ Excess movement in the 
segments adjacent to a fusion, and their consequent accelerated degeneration, is considered the main hypothesis for the development of ADD. ${ }^{3}$ ADD has an incidence of from $11 \%$ to $33 \%{ }^{21}$ In our case series, the patients were accompanied for a minimum period of two years, with an average of 41.8 months, and we did not see evidence of increased movement of the adjacent segments in dynamic radiographs. We believe this preserves the adjacent discs and reduces the incidence of ADD. In our study we found a $3.24 \%$ incidence of ADD where surgery was necessary. Nonetheless, degenerative disease of the spine itself cannot be forgotten, and ADD can be a part of the degeneration of the patient's spine. Preservation of the function and normal movement of the spine are among the current objectives of cervical spine surgery. Techniques that maintain the anatomy of the segment and the normal mobility of the spine reduce the complications related to segment fusion.

As previously described, we observed a reduction in disc height of around $9 \% .{ }^{11}$ However, we did not confirm clinically any sign of instability such as an abnormal increase in the angulation of the segment or translation between the vertebral bodies.

Posterior foraminotomy, originally described in 1966 by Scovil$\mathrm{le}^{22}$ is also a technique in which the movement of the segment is preserved. Nevertheless, we found several common complications. Cervical pain due to the dissection and retraction of the posterior cervical musculature and postoperative paresthesia due to radicular manipulation are complications that should not be underestimated. ${ }^{23}$ Additionally, most compressions occur anteriorly to the root, a great advantage of transcorporeal foraminotomy as compared to posterior foraminotomy. In the technique described, contrary to the posterior approach, the root is not manipulated.
Percutaneous endoscopic discectomy is a minimally invasive technique that has presented good results, ${ }^{8}$ but it requires a long learning curve and is indicated for soft disc hernias. Osteophytes, migrated hernias, and hard hernias are not suitable indications, making the uses of this technique quite restricted.

The direction of tunnel creation is individualized for each case, and this provides a direct approach to the compression site. Moreover, as the starting point of the tunnel is more medial than in the techniques described above, Horner's syndrome and vertebral artery lesions are complications that, so far, have not been observed.

We agree with earlier studies and believe that this is an excellent treatment option for cervical radiculopathies. ${ }^{10,11}$ However, we know that it requires extensive anatomical knowledge and meticulous preoperative planning. Prospective studies comparing transcorporeal foraminotomy with currently recognized techniques are necessary, as our study is limited in that it is a retrospective study, conducted at only one center.

\section{CONCLUSION}

Radicular decompression via transcorporeal approach is an alternative that offers good clinical outcomes without the need for arthrodesis. Prospective randomized studies are necessary to determine the superiority of this technique as compared to those already established.

All authors declare no potential conflict of interest concerning this article.

\section{REFERENCES}

1. Herkowitz HN, Rothman RH, Simeone FA. Rothman and Simeone's the Spine. 5th ed. Philadelphia: Saunders Elsevier; 2006.

2. Jagannathan J, Shaffrey Cl, Oskouian RJ, Dumont AS, Herrold C, Sansur CA, et al. Radiographic and clinical outcomes following single-level anterior cervical discectomy and allograft fusion without plate placement or cervical collar. J Neurosurg Spine. 2008;8(5):420-8.

3. Ishihara H, Kanamori M, Kawaguchi $Y$, Nakamura H, Kimura T. Adjacent segment disease after anterior cervical interbody fusion. Spine J. 2004;4(6):624-8.

4. Fountas KN, Kapsalaki EZ, Nikolakakos LG, Smisson HF, Johnston KW, Grigoriann AA, et al. Anterior cervical discectomy and fusion associated complications. Spine (Phila Pa 1976). 2007;32(21):2310-7.

5. Kast E, Derakhshani S, Bothmann M, Oberle J. Subsidence after anterior cervical inter-body fusion. A randomized prospective clinical trial. Neurosurg Rev. 2009;32(2):207-14.

6. Ca lar YS, Bozkurt M, Kahilogullari G, Tuna H, Bakir A, Torun F, Ugur HC. Keyhole approach for posterior cervical discectomy: experience on 84 patients. Minim Invasive Neurosurg. 2007;50(1):7-11.

7. Jagannathan J, Sherman JH, Szabo T, Shaffrey Cl, Jane JA. The posterior cervical foraminotomy in the treatment of cervical disc/osteophyte disease: a single-surgeon experience with a minimum of 5 years' clinical and radiographic follow-up. J Neurosurg Spine. 2009;10(4):347-56

8. Kim DH, Choi G, Lee SH. Endoscopic spine proceduresed. New York: Thieme; 2011.

9. Jho HD, Kim WK, Kim MH. Anterior microforaminotomy for treatment of cervical radiculopathy: part 1--disc-preserving "functional cervical disc surgery". Neurosurgery. 2002;51(Suppl 5):S46-53.

10. Choi G, Lee SH, Bhanot A, Chae YS, Jung B, Lee S. Modified transcorporeal anterior cervical microforaminotomy for cervical radiculopathy: a technical note and early results. Eur Spine J. 2007;16(9):1387-93

11. Choi G, Arbatti NJ, Modi HN, Prada N, Kim JS, Kim HJ, et al. Transcorporeal tunnel approach for unilateral cervical radiculopathy: a 2-year follow-up review and results. Minim Invasive Neurosurg. 2010;53(3):127-31.

12. Smith GW, Robinson RA. The treatment of certain cervical-spine disorders by an- terior removal of the intervertebral disc and interbody fusion. J Bone Joint Surg Am. 1958;40(3):607-24

13. Cloward RB. The anterior approach for removal of ruptured cervical disks. J Neurosurg. 1958:15(6):602-17.

14. Riley LH 3rd, Skolasky RL, Albert TJ, Vaccaro AR, Heller JG. Dysphagia after anterior cervical decompression and fusion: prevalence and risk factors from a longitudinal cohort study. Spine (Phila Pa 1976). 2005;30(22):2564-9.

15. Fujibayashi S, Neo M, Nakamura T. Stand-alone interbody cage versus anterior cervical plate for treatment of cervical disc herniation: sequential changes in cage subsidence. $J$ Clin Neurosci. 2008;15(9):1017-22.

16. Dimitriou R, Mataliotakis GI, Angoules AG, Kanakaris NK, Giannoudis PV. Complications following autologous bone graft harvesting from the iliac crest and using the RIA: a systematic review. Injury. 2011;42(Suppl 2):S3-15.

17. Jho HD. Microsurgical anterior cervical foraminotomy for radiculopathy: a new approach to cervical disc herniation. J Neurosurg. 1996;84(2):155-60.

18. Verbiest $\mathrm{H}$. A lateral approach to the cervical spine: technique and indications. J Neurosurg. 1968;28(3):191-203.

19. Elsawaf A, Mastronardi L, Roperto R, Bozzao A, Caroli M, Ferrante L. Effect of cervical dynamics on adjacent segment degeneration after anterior cervical fusion with cages. Neurosurg Rev. 2009;32(2):215-24.

20. Hilibrand AS, Carlson GD, Palumbo MA, Jones PK, Bohlman HH. Radiculopathy and myelopathy at segments adjacent to the site of a previous anterior cervical arthrodesis. J Bone Joint Surg Am. 1999;81(4):519-28.

21. Komura S, Miyamoto K, Hosoe H, linuma N, Shimizu K. Lower incidence of adjacent segment degeneration after anterior cervical fusion found with those fusing C5-6 and C6-7 than those leaving C5-6 or C6-7 as an adjacent level. J Spinal Disord Tech. 2012;25(1):23-9.

22. Scoville WB. Types of cervical disk lesions and their surgical approaches. JAMA. 1966;196(6):479-81.

23. Zeidman SM, Ducker TB. Posterior cervical laminoforaminotomy for radiculopathy: review of 172 cases. Neurosurgery. 1993;33(3):356-62. 